\title{
A study on knowledge of breast feeding and effect of antenatal counselling on exclusive breast feeding in primigravida mothers
}

\author{
Kamlesh Tiwari $^{1 *}$, Neha Savarna ${ }^{2}$, Ishmat Khanam ${ }^{1}$
}

\begin{abstract}
${ }^{1}$ Department of Obstetrics and Gynaecology, Vardhman Institute of Medical Sciences, Bihar, India
${ }^{2}$ Department of Preventive and Social Medicine, Darbhanga Medical College, Bihar, India
\end{abstract}

Received: 06 June 2018

Accepted: 29 June 2018

\author{
*Correspondence: \\ Dr. Kamlesh Tiwari, \\ E-mail: tiwarikamlesh_2@rediffmail.com
}

Copyright: (c) the author(s), publisher and licensee Medip Academy. This is an open-access article distributed under the terms of the Creative Commons Attribution Non-Commercial License, which permits unrestricted non-commercial use, distribution, and reproduction in any medium, provided the original work is properly cited.

\section{ABSTRACT}

Background: Exclusive breastfeeding up to 6 months of age is very beneficial not only to baby and mothers, but also to the family, society and the whole nation. In spite of best efforts by various organizations at government and NGO levels, the counselling for breast feeding during ante natal period is almost an unaddressed arena, which if proper attention is given, may result in very high incidence of successful breast feeding.

Methods: It is a hospital based prospective study. A total of 150 primiparous mothers (100 study group and 50 control group) were counselled during every antenatal checkup for exclusive breast feeding attending the OPD of Obstetrics \& Gynaecology department of Vardhman Institute of Medical sciences, Pawapuri, Nalanda, Bihar from January 2015 to December 2016 and the outcome of counselling was observed during follow up in puerperium for 6 weeks.

Results: Similar profile primiparous mothers in both study and control group, the mothers who were counselled on their antenatal visit for exclusive breast feeding, the success rate was much higher in counselled group than study group ( $\mathrm{p}$ value 0.0001 ). It was also observed that the prior information about breast feeding were provided by electronic media, papers and family members and in this regard contribution of health system is minimal.

Conclusions: Every obstetrician and other care givers must include routine care of breast and counselling on breast feeding during antenatal check up to enhance the confidence of primiparous mothers. A few extra minutes spared in counselling on breast feeding has a long-lasting effect on successful breast feeding during the post-natal period.

Keywords: Ante natal counselling, Exclusive breast feeding, Role of care givers

\section{INTRODUCTION}

"A newborn baby has only three demands. They are warmth in arms of its mothers, food from her breasts and security in the knowledge of her presence. Breastfeeding satisfies all the three" Dickregrantly

Exclusive breastfeeding is defined as "an infant's consumption of human milk with no supplementation of any type of liquid (no water, no juice, no nonhuman milk and no foods) except for vitamins, minerals and medications. ${ }^{1}$ In many countries, including ours, the United States, UK, Canada etc, daily vitamin D supplementation is recommended for all breastfed infants After solids are introduced at around six months of age, continued breastfeeding is recommended..$^{2-4}$

The AAP recommends that babies be breastfed at least until 12 months or longer if both the mother and child wish. ${ }^{5} \quad$ WHO's guidelines recommend continued frequent, on-demand breastfeeding until two years of age or beyond. ${ }^{6,7}$ Despite strong evidences in support of Exclusive Breast Feeding (EBF) for the first six months of life, its prevalence has remained low worldwide and it is estimated that only about one-third of infants were exclusively breastfed for the first six months of life. ${ }^{8-11}$ 
Primiparous mothers may have some anxiety because they aren't quite sure how to breastfed. Rather than becoming anxious about it, the mothers need to learn all things about breast feeding process

According to the Centre for Disease Control and prevention (CDC), one of the most highly effective preventive measures a mother can take to protect the health of her infant is to breastfeed. The success rate among mothers who want to breastfeed can be greatly improved through active support from their families, friends, communities, clinicians, health care leaders, employers, and policymakers. Given the importance of breastfeeding for the health and well-being of mothers and children, it is critical that we take action across the country to support breastfeeding. In India, breastfeeding appears to be influenced by social, cultural, and economic factors. In 1991, Breastfeeding Promotion Network of India (BPNI) was born to protect, promote and support breastfeeding. ${ }^{12}$

Further, the Government of India has undertaken National Rural Health Mission, which intends to implement Integrated Management of Neonatal and Childhood Illnesses (IMNCI) through the existing healthcare delivery system. ${ }^{13}$ Poor practices and attitudes toward exclusive breastfeeding have been reported to be among the major reasons for poor health outcomes among children, particularly in developing countries.

Nonetheless, the promotion and acceptance of practices, such as exclusive breastfeeding, are especially important in developing countries with high levels of poverty, and that are characterized by a high burden of disease and low access to clean water and adequate sanitation. ${ }^{14}$ The Aim of the present study is to assess the knowledge regarding exclusive breast feeding among primigravida mothers and the effect of ante natal counselling on exclusive breast feeding.

\section{METHODS}

This was a cross sectional study carried out among expecting primiparous mothers who were attending the ante natal clinic, in the department of Obstetrics and Gynaecology, Vardhman Institute of Medical Sciences, Pawapuri, Nalanda, Bihar, India during the period from January 2015 to December 2016. Participants were selected and registered through a random sampling method of the database of expecting mothers attending ANC in the outpatient department. Those mothers diagnosed as HIV and Hepatitis B positive, have Psychosis, coming first time in late 3rd trimester and those not willing to participate in the study were excluded. Then participants were randomly divided in study and control group and they were interviewed by a fixed pretested questionnaire. On each visit the mothers of study group were positively counselled for exclusive breast feeding and special attention were paid to the guardians accompanying them. The mothers after delivery were encouraged to come for checkup during puerperium and enquired regarding feeding of infants up to 6 weeks of delivery. Data was collected in Microsoft Excel sheets and statistical analysis was done to compare significance between two groups ( $p$ value was calculated using $\mathrm{z}$ score for proportions).

\section{RESULTS}

$74 \%(56 \%+18 \%)$ and $72 \%(52 \%+20 \%)$ mothers were in the age range of $16-22 \mathrm{yrs}$ in study and control group respectively. Only $6 \%$ mothers in study group and $16 \%$ in control group were more than 26 years. Only $20 \%$ mothers in study group and $22 \%$ mothers in control group were had educational qualification of 10th standard and above, while $48 \%$ and $56 \%$ mothers had primary education in study and control group respectively.

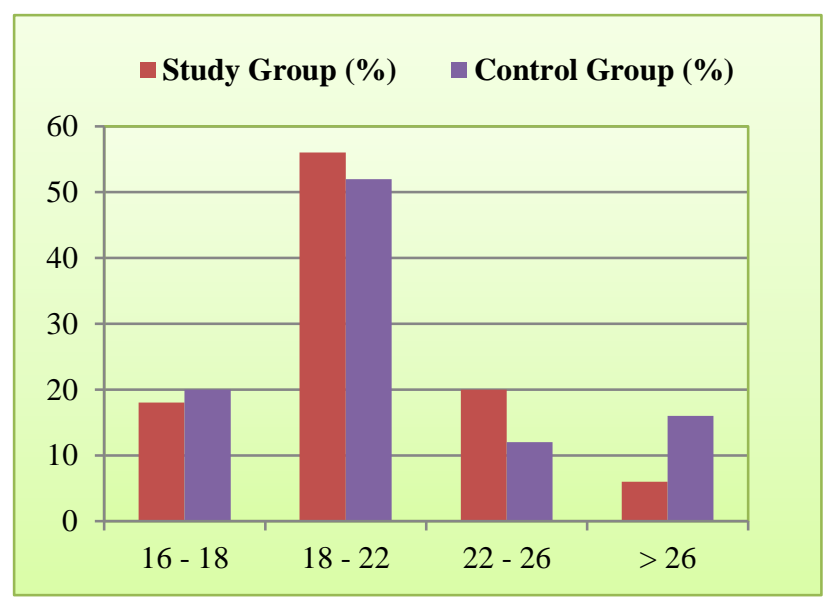

Figure 1: Age distribution.

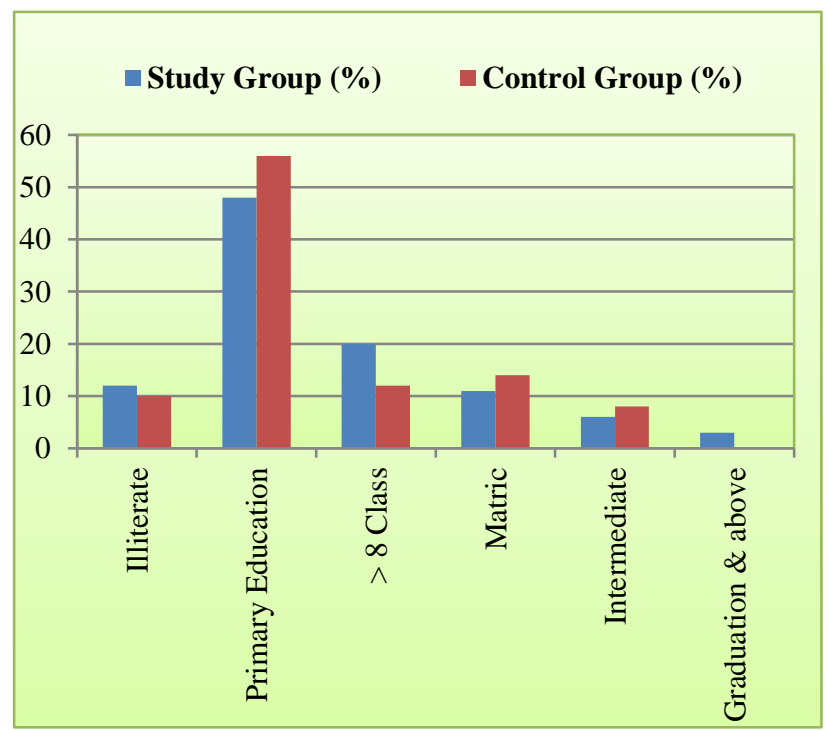

Figure 2: Educational qualification.

$3 \%$ mothers in study group had graduated in study, while none of the mothers were graduate in control group. $82 \%$ mothers in study group and $84 \%$ in control group were 
Hindu, while muslims were respectively $18 \%$ and $16 \%$. Majority of mothers $96 \%$ in study group and $100 \%$ in control group belonged from joint families. Mothers in both study and control group had some knowledge about benefit of breast feeding ( $48 \%$ \& $30 \%$ respectively), but only $18 \%$ mothers in both groups had knowledge of exclusive breast feeding. Also, knowledge about colostrums had very poor in mothers of both groups. Knowledge about complementary feeding was much higher $(76 \%)$ in study than control group (32\%).

As mothers for this study were enrolled in different phases of Ante natal checkup, the source of knowledge regarding breast feeding and exclusive breast feeding were assessed before starting counselling.

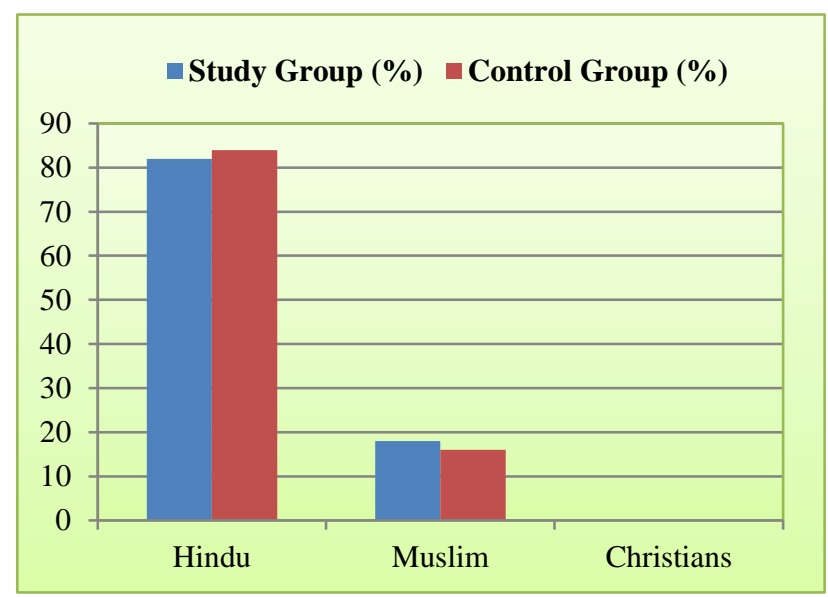

Figure 3: Religion.

Audio visual aids and books (96\% in study group and $94 \%$ in control group) and family members (88\% in study group \& $84 \%$ in control groups) were the main source of information providers (96\%) about breast feeding. Unfortunately, medical personnel had very little (18\%) contribution in providing information. Mode of delivery were similar $87 \% / 84 \%$ and $13 \% / 16 \%$, normal vaginal delivery/ LSCS in study and control group.

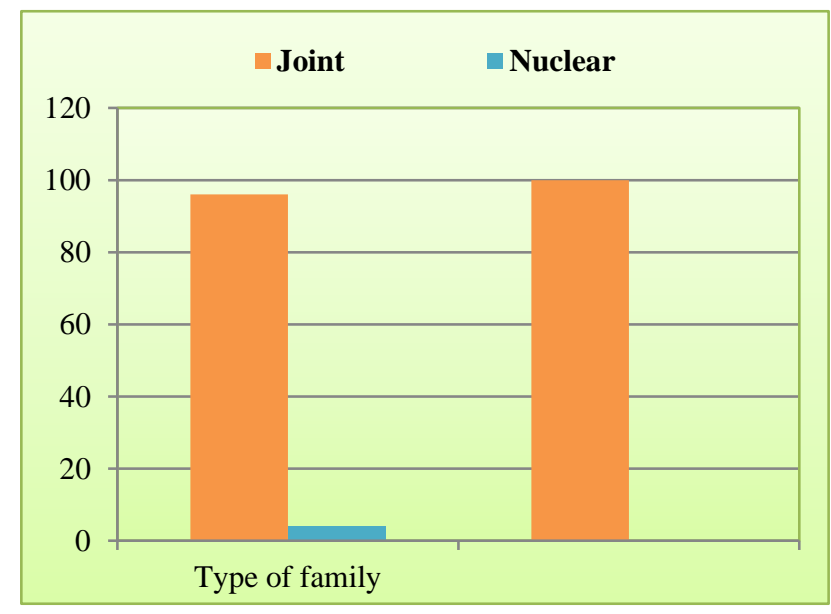

Figure 4: Type of family.
But the effect of counseling for exclusive breast feeding were statistically much significant. $90.8 \%$ mothers in normal vaginal delivery and $61.5 \%$ in LSCS delivered mothers were successfully breast feeding exclusively to their babies, while in non counseled group mothers only $61.9 \%$ in normal vaginal delivered mothers and only $37.5 \%$ in LSCS delivered mothers were breast feeding exclusively.

Table 1: Assessment of knowledge of mother's about breast feeding.

\begin{tabular}{|lll|}
\hline Characteristic & $\begin{array}{l}\text { Study } \\
\text { group }\end{array}$ & $\begin{array}{l}\text { Control } \\
\text { group }\end{array}$ \\
\hline $\begin{array}{l}\text { Knowledge of Colostrums } \\
\text { Knowledge about benefit of breast } \\
\text { milk }\end{array}$ & 10 & 12 \\
\hline $\begin{array}{l}\text { Knowledge of exclusive breast } \\
\text { feeding }\end{array}$ & 18 & 30 \\
\hline $\begin{array}{l}\text { Knowledge of complementary } \\
\text { feeding }\end{array}$ & 76 & 32 \\
\hline
\end{tabular}

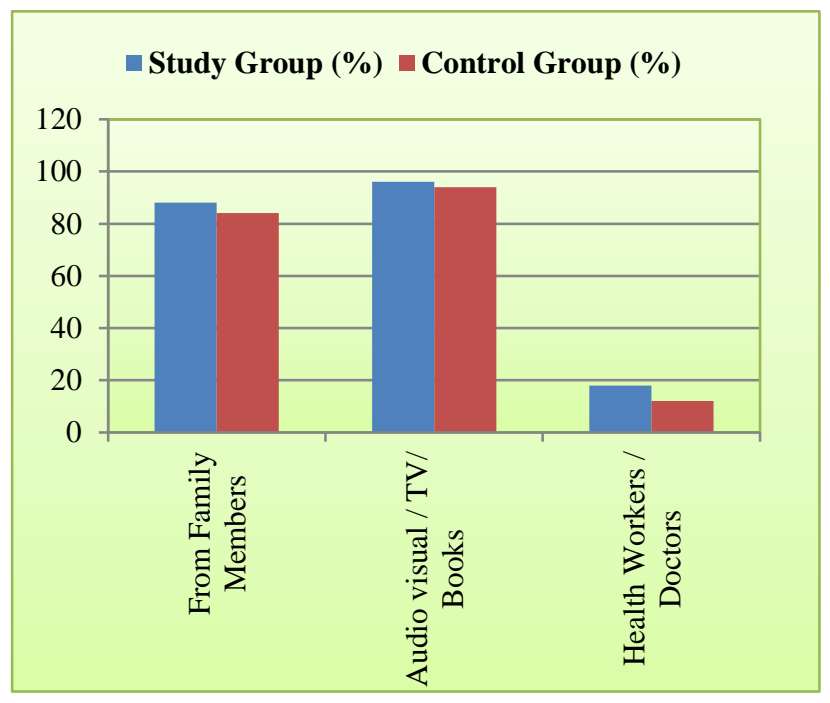

Figure 5: Source of knowledge about breast feeding.

Table 2: Exclusive breast feeding up to 6 weeks after delivery.

\begin{tabular}{|c|c|c|c|c|}
\hline & \multicolumn{2}{|c|}{ Study group } & \multicolumn{2}{|c|}{ Control group } \\
\hline & $\begin{array}{l}\text { Normal } \\
\text { delivery }\end{array}$ & LSCS & $\begin{array}{l}\text { Normal } \\
\text { delivery }\end{array}$ & LSCS \\
\hline $\begin{array}{l}\text { Mode of } \\
\text { delivery }\end{array}$ & $\begin{array}{l}\mathrm{N}=87 \\
(87 \%)\end{array}$ & $\begin{array}{l}N=13 \\
(13 \%)\end{array}$ & $\begin{array}{l}\mathrm{N}=42 \\
(84 \%)\end{array}$ & $\begin{array}{l}N=8 \\
(16 \%)\end{array}$ \\
\hline EBF & $\begin{array}{l}\mathrm{N}=79 \\
(90.8 \%)\end{array}$ & $\begin{array}{l}\mathrm{N}=8 \\
(61.5 \%)\end{array}$ & $\begin{array}{l}\mathrm{N}=26 \\
(61.9 \%)\end{array}$ & $\begin{array}{l}\mathrm{N}=3 \\
(37.5 \%)\end{array}$ \\
\hline
\end{tabular}

\section{DISCUSSION}

The future of any nation depends on the children. Healthy children, both physically and mentally will make a nation healthy and wealthy. Nature has provided every species specific nutritive resource to nurse their offspring's. It is our duty to propagate this fact to every 
person of the society. The basic and most natural wonderful food for infant feeding is mother's milk, which is adequate for the first six months of life. After six months of exclusive breast feeding complimentary food must be initiated for further optimum growth. There are various misconceptions among mothers and family members regarding breast feedings.

Most of the studies reported that mothers were not having adequate knowledge regarding breast feeding. Keeping in mind these facts the present study was undertaken with an objective to assess the knowledge regarding breastfeeding among prim gravida mothers.

More than $70 \%$ mothers were in the age group of 16-22 years. Among those more than $60 \%$ had educational level below primary education. Although most of the mothers were Hindu $(82 \%)$, but no significant variations were found between Hindu and Muslims. There was poor prior knowledge about breast feeding, exclusive breast feeding among mothers of various socio-economic group and varying educational levels without any significant difference. Most unfortunate finding in this study was that whatever knowledge about breast feeding, exclusive breast feeding, and complimentary feedings were there, the role of imparting knowledge by medical fraternity was minimal $(18 \%)$. Electronic media/ books etc. were the main source of knowledge $(96 \%)$ followed by family members $(84 \%)$.

But after repeated counselling during antenatal checkup dramatic improvement in exclusive breast feeding among mothers of study group was observed. $90 \%$ mothers having vaginal delivery and $62 \%$ mothers having LSCS were successfully breastfeeding exclusively to their babies up to six weeks after delivery while only $62 \%$ mothers having normal vaginally delivered and $38 \%$ having LSCS in control group were breastfeeding exclusively their babies during the same period.

Present study correlates with most of the previous studies which have assessed about the knowledge, attitude and technique of breast feeding and has almost similar findings. The study done by Sharma E et al, John R, Khan et al, Bada M et al, Slama BF et al all have almost similar observations. ${ }^{15,16,18,19}$

In the present study it was observed that out of 100 mothers in study group, 87 had normal vaginal delivery and 13 had LSCS. Out of 87 normal vaginal delivery 79 mothers and out of 13 LSCS 8 mothers had successful exclusive breast feeding up to 6 weeks in puerperium, (while in control group out of 42 normal vaginal delivery 26 mothers and out of 8 LSCS 3 mothers had exclusive breast feeding up to 6 weeks in puerperium). Total no mothers having successful exclusive breastfeeding in study group was $87(n=100)$, while in control group this no was $29(\mathrm{n}=50)$ [ $\mathrm{p}$ value $<0.0001$ (calculated using $\mathrm{z}$ score for proportions)]). Statistically the outcome of ante natal counselling on exclusive breast feeding in study group is having significant value ( $\mathrm{p}$ value $<0.0001$ ). As medical fraternity, while doing antenatal checkup usually do not care to provide sufficient and regular information regarding benefits of breast feeding, the expected benefit of exclusive breast feeding to babies and mothers in society is low. It was observed that the easy accessibility of television, social medias and other audio-visual aids have better contribution in educating the society.

Similar observation was made by Ahmad MO et al (2012). ${ }^{20}$ They found that as compared to the not counselled group, the mothers who initiated breastfeeding immediately after birth were statistically significantly higher $(\mathrm{p}<0.046)$ in the counselled group $(84 \%$ and $96 \%)$. Similarly, the number of counseled mothers who practiced exclusive breastfeeding was statistically very highly significantly more $(\mathrm{p}<0.001)$ than the not counselled group (68\% and $16 \%$ respectively).

Gunashekharan et al in the similar study have observed that during routine antenatal counseling $79 \%$ booked mothers had not received any specific counselling regarding breast feeding. ${ }^{21}$ They conclude that Awareness related to breastfeeding among mothers in the "counselled" group was better than those in the "not counselled" group. Even in the "counselled" group, awareness among mothers with regard to correct breastfeeding technique and concept of continuing breastfeeding during illness in the baby was no different from those in the "not counselled" group. They further conclude that antenatal counselling helps in motivating the mothers for initiation of breastfeeding immediately after birth and practicing exclusive breastfeeding for first six months of infant's life. Existing antenatal counselling on breastfeeding is inadequate in the population studied and needs to be strengthened.

In an article published in www.Clinical Trials. Gov, NCT002770192 the authors conclude that Where breastfeeding practices are suboptimal, simple oneencounter antenatal education and counselling significantly improve breastfeeding practice up to 3 months after delivery. ${ }^{22}$ Provision of printed or audio visual educational material is not enough. Health care workers should make every effort to have one face-toface encounter to discuss breastfeeding with expectant mothers before they deliver.

\section{CONCLUSION}

With the statistically significant finding of ante natal counselling on breast feeding in primiparous mothers on exclusive breast feeding subsequently, it can be concluded that every obstetrician and other care givers must include routine care and counselling on breast feeding during ante natal check-up. The authors strongly recommend that the opportunity provided during routine antenatal care of mothers, few extra minutes of counselling regarding breast feeding will have a longlasting effect on successful breast feeding to babies 
during post-natal period. If we obstetrician and other care givers provide the essential information to expecting mothers, the success rate of exclusive breast feeding will be much higher, which will not only be very beneficial to the neonates but to mothers, family, society and the nation. As said by Pamela K Wiggins that "Breast feeding is a mother's gift to herself, her baby and the earth" we obstetrician must deliver our best to promote a successful breast-feeding practice. More and more studies are needed to validate such type of studies and to boost the efforts of all organizations involved in promoting breast feeding.

\section{ACKNOWLEDGMENTS}

We acknowledge the resident doctors and nursing staffs working in the department of Obstetrics \& Gyanecolgy, Vardhman Institute of Medical Sciences, Pawapuri, for their contribution data collection, counselling of mothers and other paper works. Dr. Neha has done the work of data analysis.

\section{Funding: No funding sources}

Conflict of interest: None declared

Ethical approval: The study was approved by the Institutional Ethics Committee

\section{REFERENCES}

1. The World Health Organization's infant feeding recommendation. Global strategy on IYCF (WHA 55 A55/15, \& WHA54 A54/INF.DOC./4)

2. American Academy of Pediatrics. (2012, February27). Breastfeeding and the use of human milk (policy statement) pediatrics 129, e827-e841 Retrieved April 27, 2017.

3. World Health Organization. (2001, May1). the world Health Organization's infant feeding recomendation. retrieved June 13, 2012.

4. John C. Godel Canadian Paediatric Society, First Nation, Inul and Metis Health Committee paediatr Child Health Vitamin D Supplementation Recommendations for Canadian mothers and infants. 2001:12(7):583-9.

5. Wagner CL, Greer FR. American Academy of Pediatrics Section on Breastfeeding. Breastfeeding and the use of human milk. Pediat. 2012;129(3):e827-41.

6. Organisation mondiale de la santé. Département santé et développement, World Health Organisation Staff, World Health Organization, UNICEF.. Global strategy for infant and young child feeding. World Health Organization; 2003.

7. Breastfeeding. Archived from the original on 20 $\begin{array}{llll}\text { February 2016. Available at } & \text { 20 }\end{array}$ www.nhs.uk/conditions/pregnancy-and-baby/vitaminsfor-children

8. Li R, Darling N, Maurice E, Barker L, GrummerStrawn LM. Breastfeeding rates in the United States by characteristics of the child, mother or family: the 2002 National Immunization Survey. Pediat. 2005;115:31-7.

9. Agampodi SB, Agampodi TC, Piyaseeli UK. Breastfeeding practices in a public health field practice area in Sri Lanka: a survival analysis. Int Breastfeed J. 2007;11:13.

10. Cai X, Wardlaw T, Brown DW. Global trends in exclusive breastfeeding. Int Breastfeed J. 2012;28:12.

11. WHO. The WHO Global Data Bank on Infant and Young Child Feeding. WHO Nutrition for Health and Development; 2009. (Cited 2014 July 21). Available from: http://www.who.int.

12. Gupta A. BPNI: 10 years of its work. J Indian Med Assoc. 2002;100:512-5.

13. NRHM. National Rural Health Mission (2005-2012) Mission document. New Delhi: MOHFW, Government of India, New Delhi; Ministry of Health and Family Welfare (MoHFW); 2006.

14. Magawa R. Knowledge, attitudes and practices regarding exclusive breastfeeding in Southern AfricaPart 2. 2012. (Cited 2014 July 21). Available at http://www.consultancyafrica.com

15. Sharma E, Seelan S. Knowledge Regarding Breastfeeding Among Primigravida Mothers. International J Rec Sci Res. 2017;8(11):21517-21.

16. John R. Knowledge, attitude and practices of employed mothers about breast feeding. J Nurs Res. 2005;96(4):21-5.

17. Rempel LA, Rempel JK. The breastfeeding team: the role of involved fathers in the breastfeeding family. Journal of Human Lactation. 2011;27(2):115-21.

18. Mbada CE, Olowookere AE, Faronbi JO, OyinlolaAromolaran FC, Faremi FA, Ogundele AO, et al. Knowledge, attitude and techniques of breastfeeding among Nigerian mothers from a semi-urban community. BMC Res Notes. 2013;6(1):552.

19. Ben Slama F, Ayari I, Ouzini F, Belhadj O, Achour N. Exclusive breastfeeding and mixed feeding: knowledge, attitudes and practices of primiparous mothers. East Mediterr Health J. 2010;16(6):630-5.

20. Ahmad MO, Sughra U, Kalsoom U, Imran M, Hadi U. Effect of antenatal counselling on exclusive breastfeeding. J Ayub Med Coll Abbottabad. 2012;24(2):116-9.

21. Dhandapany G, Bethou A, Arunagirinathan A, Ananthakrishnan S. Antenatal counseling on breastfeeding-is it adequate? A descriptive study from Pondicherry, India. Int Breastfeed J. 2008;3(1):5.

22. Mattar CN, Chong YS, Chan YS, Chew A, Tan P, Chan $\mathrm{YH}$, et al. Simple Antenatal Preparation to Improve Breastfeeding Practice. Obstet Gynecol. 2007 109(1):73-80.

Cite this article as: Tiwari K, Savarna N, Khanam I. A study on knowledge of breast feeding and effect of antenatal counselling on exclusive breast feeding in primigravida mothers. Int J Reprod Contracept Obstet Gynecol. 2018;7:3311-5. 